\title{
Identification of Carbon Black in Military Textiles Using Infrared Imaging Techniques
}

\author{
J. R. Andrés, R. Hidalgo-Gato, J. M. López-Higuera, F. J. Madruga \\ Photonic Engineering Group, University of Cantabria, Santander, Spain \\ Email: andresjr@unican.es
}

Received April 23, 2013; revised June 8, 2013; accepted July 11, 2013

Copyright (C) 2013 J. R. Andrés et al. This is an open access article distributed under the Creative Commons Attribution License, which permits unrestricted use, distribution, and reproduction in any medium, provided the original work is properly cited.

\begin{abstract}
The carbon black has been used in military fabrics to comply with the color requirements and infrared radiation lessening criteria. Currently, military industries don't distinguish between fabrics with carbon black fibers or with carbon black into dyes or prints. The latter initially allows us to comply with the color specifications in the visible and infrared, but fabrics are degraded with use losing that initial capacity. The inclusion of carbon black in the fiber gets that the fabric doesn't degrade with the wear, washed and dried, ensuring the accomplishment of the specifications all the time. The use of infrared imaging will allow us to define a method to discriminate those textiles with carbon black in their fibers from those which are dyed or printed.
\end{abstract}

Keywords: Military Textiles; Fabrics; Infrared Imaging; Step-Heating; Carbon Black; Thermal Response

\section{Introduction}

Soldiers of the same army are dressed similarly since ancient, but also vividly, vividly, due to the necessity of identifying the enemy in close combat or in the midst of the battle. In the period from the First to the Second World War, war powers began to develop uniforms more suitable for the combat scenarios of the time. It is clear that a showy uniform can be associated with a higher number of casualties in the army in the trench warfare, as happened with the French army in First World War when they used the same splendid blue and red bright color uniforms they had used in the Franco Prussian War.

Currently, the military industry requires uniforms with specific features aimed at masking its troops. These features that limit or prevent the detection of the soldiers are divided into different categories: the visual, infrared, olfactory, radar, sonic and hearing. This study will treat the infrared category within the military masking techniques.

Carbon black has been implemented in military uniforms for several decades [1]. Carbon black has the ability to absorb radiation in the near infrared spectrum, so the soldiers can be hidden at night and infrared cameras can't detect them because the fabrics absorb the infrared radiation generated by the human body heat. These uniforms are made with fabrics and/or fibers which have been previously treated to include carbon black [2].

This gives rise to a problem, when thinking about night camouflage, the uniform should be also useful throughout its lifetime, what justifies the development of this study. Fabrics treated with dyes or stampings including carbon black will lost such treatment due to use, washing and drying, thus losing their ability to absorb the infrared radiation. However, if the carbon black is inserted into the fibers forming the fabric it will not be degraded or eliminated with the uniform wear.

Although nowadays control institutions (laboratories and armies) do not take into account the requirement of black carbon in fiber and validate all fabrics that are in agreement with the color specifications both in the visible and infrared ranges, this will probably change in the future due to the requirements of durability of the uniforms.

In this regard, a method for the detection of fabrics with black carbon in fibers is defined, that can be used in the military scenario to help differentiating them from those fabrics that have undergone a dye or print process.

In the paper, Infrared imaging with some associated processing is used to determine the presence of carbon black in fibers or fabrics as a function of the thermal response obtained with specific excitations that provide heat to samples. 


\section{Three Processing for Carbon Black}

As mentioned before, carbon black may be incorporated into the fabrics through three processing:

- For printing;

- For tincture;

- In the fiber.

The distribution of the carbon black varies depending on the processing (printing, tincture, inside fiber), Figure 1. In the case of printing, the carbon black is distributed only on the surface side of the fabric. In the other two processing, the carbon black is distributed throughout the fabric, with the difference that in the case of dyeing their distribution is random, while in the case of the fiber it presents a uniform distribution.

In terms of the use of carbon black for military garment to prevent overnight detection, the key is in the life cycle of the military uniform, in the wear itself, washing and drying. Only those with carbon black into the fibers will ensure infrared absorption throughout all its life cycle.

The approval test of the fabrics checks their re-emission and verifies their fit to the curves defined in different spectral ranges and for each of the colors of camouflage fabric. These tests are passed by fabrics that incorporated carbon black for any of the three methods described.

\section{Fibers and Fabrics}

Eight different fabrics were chosen for this study: four raw fabrics and four finished comprising various combinations to determine their behavior with carbon black in the fiber, warp or weft, tincture or printing. The fibers have a thickness of 30 microns and the finished fabric between $1-3 \mathrm{~mm}$, being the sample size of $120 \times 100$ $\mathrm{mm}^{2}$.

The study was performed on 5 different types of fibers, one with pure cotton and the remaining with fibers of polyamide and polyester with and without carbon black. The following table, Figure 2, summarizes the identification and the main characteristics of each sample.

\section{Methodology}

This study is to detect the presence of carbon black in military fabrics identifying those with carbon black fibers and therefore discriminating them from those with car-

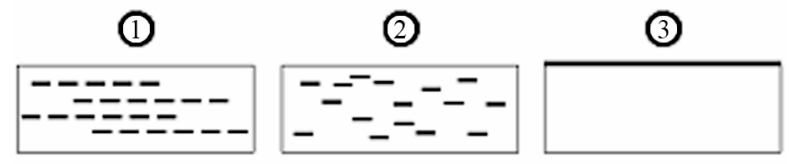

Figure 1. (1) In the fiber 2 For tincture 3 For printing.

\begin{tabular}{|c|c|c|}
\hline ID. & $F A B R I C$ & COMPOSITION \\
\hline COPA dp & & $\begin{array}{l}\mathrm{CB} \text { in dyeing and printing } \\
92 \% \mathrm{CO}, 8 \% \mathrm{PA} \text { white }\end{array}$ \\
\hline COPA w & & $\begin{array}{c}\text { CB in warp fiber } \\
\text { Warp: } 70 \% \text { CO, } 20 \% \text { PA white, } \\
10 \% \text { PA grey } \\
\text { Weft: } 70 \% \text { CO, 30\% PA white }\end{array}$ \\
\hline COPA wp & & $\begin{array}{c}\text { CB in warp and printing } \\
\text { Warp: } 70 \% \text { CO, } 20 \% \text { PA white, } \\
10 \% \text { PA grey } \\
\text { Weft: } 70 \% \text { CO, 30\% PA white }\end{array}$ \\
\hline COPES dp & & $\begin{array}{l}\text { CB in dyeing and printing } \\
50 \% \mathrm{CO}, 50 \% \mathrm{PES} \text { white }\end{array}$ \\
\hline COPES & & $\begin{array}{c}\text { Without CB } \\
33 \% \text { CO, } 67 \% \text { PES white }\end{array}$ \\
\hline COPA w & & $\begin{array}{c}\text { CB in warp fiber } \\
\text { Warp: } 70 \% \text { CO, } 20 \% \text { PA white, } \\
10 \% \text { PA grey } \\
\text { Weft: } 70 \% \text { CO, 30\% PA white }\end{array}$ \\
\hline $\mathrm{CO}$ & & $\begin{array}{l}\text { Without CB } \\
100 \% \mathrm{CO}\end{array}$ \\
\hline $\begin{array}{l}\text { COPES } \\
\text { we }\end{array}$ & & $\begin{array}{c}\text { CB in weft } \\
67 \% \text { CO, 33\% PES grey }\end{array}$ \\
\hline
\end{tabular}

Figure 2. Main characteristics of samples (CB: carbon black; CO: Cotton; PA: Polyamide; PES: Polyester; d: dyeing; p: printing; w: warp; we: weft; white: without $C B$; grey: with $\mathrm{CB})$.

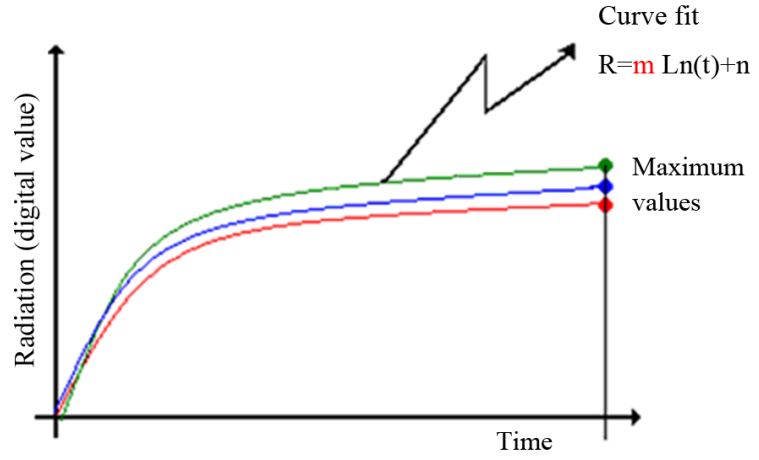

Figure 3. Pair of values: Maximum value and slope “ $m$ ”.

bon black in the dyeing or printing.

The chosen technique is infrared imaging $[3,4]$, to find 


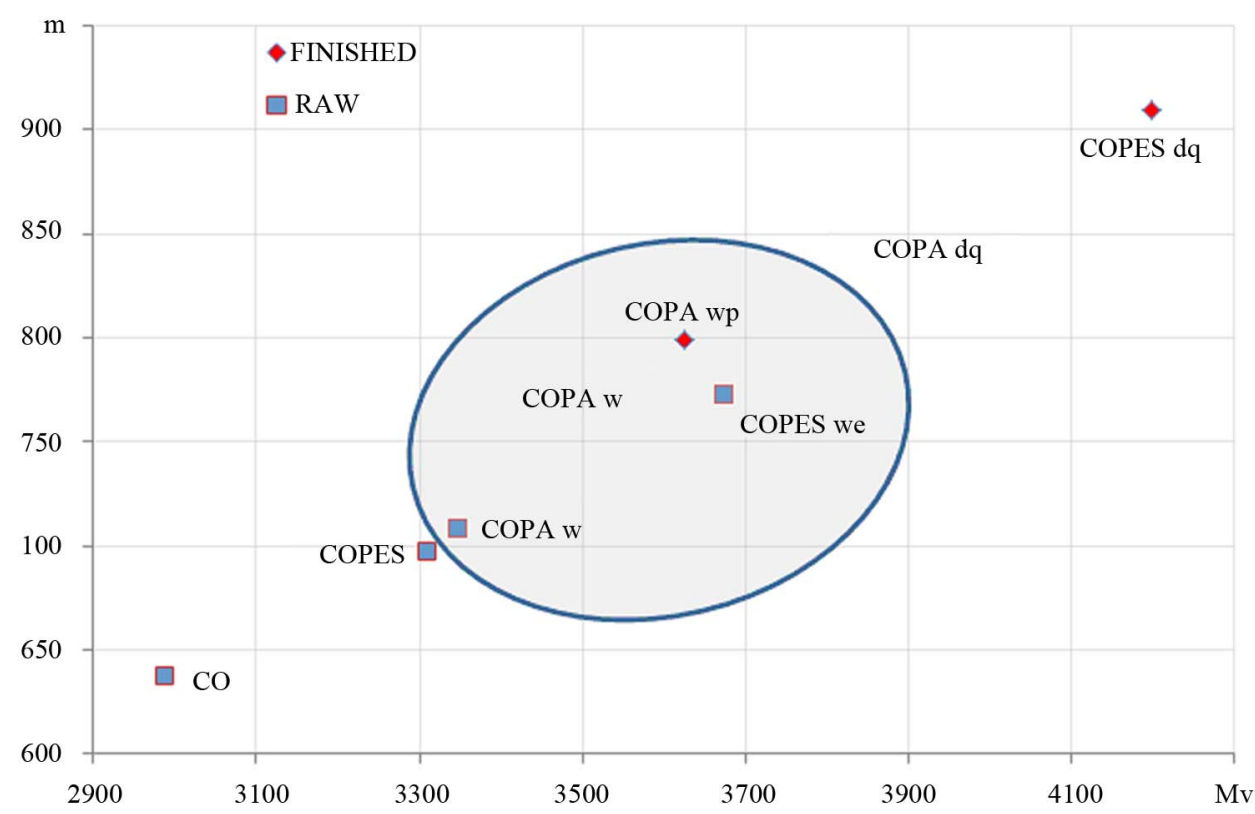

Figure 4. Pairs of values obtained in the tests.

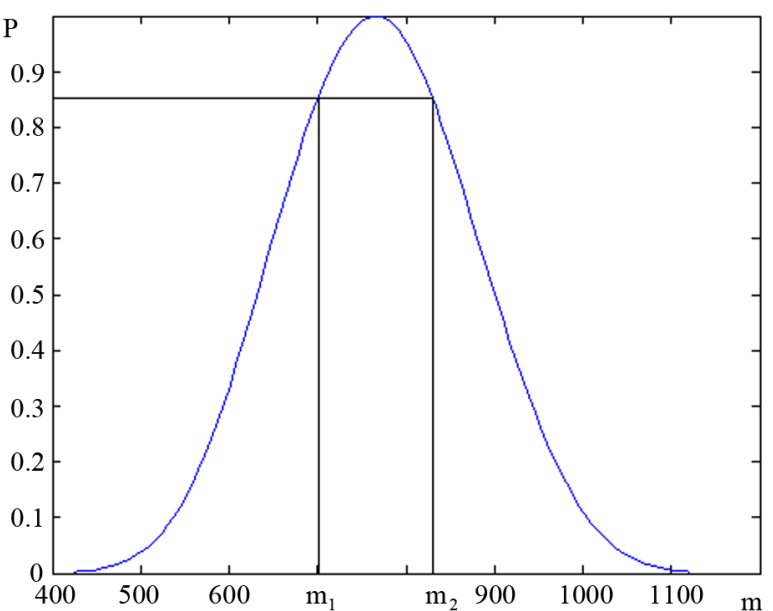

Figure 5. Density distribution with “m” and “p” values.

a thermal response detectable by the camera, analyze it and compare it with those captured for all the samples. To achieve this a thermal excitation to provide heat to the sample is needed, thus generating a thermal response in terms of the thermal properties of the samples, allowing to distinguish between the ones that have carbon black in fibers from those where it is included in the dye or prints [5].

Two different excitations have been tested, pulsed thermography and step-heating thermography [6]. It was found that the best results were obtained with the stepheating thermography and, consequently, the study was conducted with this excitation using two pairs of heat sources of total power $2.6 \mathrm{~kW}$.
The step-heating thermography method consists of a prolonged heating of the sample for a given time, and of a capture of a thermographic sequence of pictures. The camera captures the radiation emitted by the sample surface, for both heating and cooling. Once the thermographic sequence has been preprocessed, different characteristic parameters of each test could be studied using the specific processing.

To analyze the thermal response, Figure 3, a natural logarithmic curve fit has been chosen to capture two values: the maximum value and the slope of the curve, drawing a graph with this pair of values to compare each sample. Fabrics with carbon black in fibers were identified, and also those with carbon black dyes or printings on the other.

The comparative study of the pairs of values in the same graph, Figure 4, shows that there are three distinct regions corresponding to the values of fabrics without carbon black, with black carbon in fiber and with carbon black in dyeings and printings.

Once that is has been observed that each area is characteristic for each type of fabric, the process can be automated through the multivariate kernel density estimation technique, which can provide the boundaries between areas using only one parameter after the determination of a density factor calculated in the design of a pattern with known characteristics samples.

To achieve this, Figure 5, the density distribution is represented and the $\mathrm{p}$ value is estimated and depicted in the vertical axis, being normalized with the maximum value of the distribution given as a fraction of unity. This 


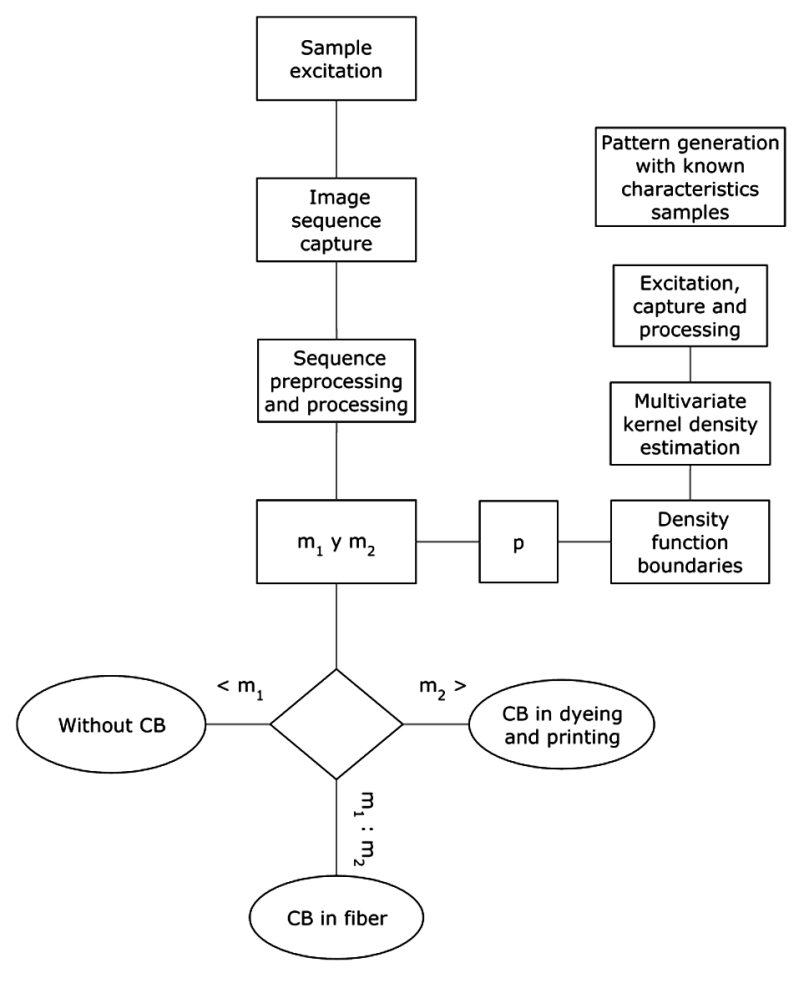

Figure 6. Decision diagram.

allows the estimation of the $m$ values, the slopes of the fitted curves. With the defined test conditions, known limits, and using a simple conditional statement, any fabric can be cataloged (Figure 6).

\section{Conclusions}

The results presented in this paper show a characteristic thermal response depending on which state the carbon black is in the fabrics. Therefore, the step-heating thermography technique is defined as the most suitable for this type of study.
It can be seen that the textiles with carbon black in the fiber are encompassed in the region limited by the maximum digital values of the captured radiation and by the slope values. In our case a p value of 0.85 and the resulting $\mathrm{m}$ limits are 706.58 and 826.27 have been estimated.

It can be concluded that it is possible to discriminate between fabrics with carbon black, depending on its location, either directly in the fiber or in the others dyeing and printing fabrics.

\section{REFERENCES}

[1] D. Li and G. Sun, "Coloration of Textiles with Self-Dispersible Carbon Black Nanoparticles," Dyes and Pigments, Vol. 72, No. 2, 2007, pp. 144-149. doi:10.1016/j.dyepig.2005.08.011

[2] M. Khajeh Mehrizi, S. M. Mortazavi, S. Mallakpour, S. M. Bidoki, M. Vik and M. Vikova, "Effect of Carbon Black Nanoparticles on Reflective Behavior of Printed Cotton/Nylon Fabrics in Visible/Near Infrared Regions," Fibers and Polymers, Vol. 13, No. 4, 2012, pp. 501-506. doi:10.1007/s12221-012-0501-5

[3] H. D. Benítez, C. Ibarra-Castanedo, A. Bendada, X. Maldague, H. Loaiza and E. Caicedo, "Procesamiento de Imágenes Infrarrojas Para la Detección de Defectos en Materiales," Tecnura, 2007. http://tecnura.udistrital.edu.co/ojs/index.php/revista/articl e/view/213/211

[4] C. J. Hellier, "Handbook of Nondestructive Evaluation," 3rd Edition, McGraw-Hill Professional, New York, 2003.

[5] P. Shull, "Nondestructive Evaluation: Theory, Techniques and Applications," Marcel Dekker, Inc., New York, 2002. doi: $10.1201 / 9780203911068$

[6] D. A. González, "Contribuciones a las Técnicas no Destructivas para Evaluación y Prueba de Procesos y Materiales Basadas en Radiaciones Infrarrojas," Ph.D. Thesis, Universidad de Cantabria, Cantabria, 2006. 